\title{
Factors influencing failure to undergo interval cholecystectomy after percutaneous cholecystostomy among patients with acute cholecystitis: a retrospective study
}

Peng Yao, Zhihui Chang ${ }^{*}$ and Zhaoyu Liu

\begin{abstract}
Background: Percutaneous cholecystostomy (PC) with interval cholecystectomy is an effective treatment modality in high-risk patients with acute cholecystitis. However, some patients still fail to undergo interval cholecystectomy after PC, with the reasons rarely reported. Hence, this study aimed to explore the factors that prevent a patient from undergoing interval cholecystectomy.
\end{abstract}

Methods: Data from patients with acute cholecystitis who had undergone PC from January 1, 2017 to December 31, 2019 in our hospital were retrospectively collected. The follow-up endpoint was the patient undergoing cholecystectomy. Patients who failed to undergo cholecystectomy were followed up every three months until death. Univariate and multivariate analyses were performed to analyze the factors influencing failure to undergo interval cholecystectomy. A nomogram was used to predict the numerical probability of non-interval cholecystectomy.

Results: Overall, 205 participants were identified, and 67 (32.7\%) did not undergo cholecystectomy during the follow-up period. Multivariate analysis revealed that having a Tokyo Guidelines 2018 (TG18) grade III status (odds ratio [OR]: 3.83; 95\% confidence interval [Cl]: 1.27-11.49; $p=0.017$ ), acalculous cholecystitis (OR: $4.55 ; 95 \%$ Cl: 1.59-12.50; $p=0.005$ ), an albumin level $<28 \mathrm{~g} / \mathrm{L}$ (OR: $4.15 ; 95 \% \mathrm{Cl}: 1.09-15.81 ; p=0.037$ ), and a history of malignancy (OR: 4.65 ; $95 \%$ Cl: $1.62-13.37 ; p=0.004$ ) were independent risk factors for a patient's failure to undergo interval cholecystectomy. Among them, the presence of a history of malignancy exhibited the highest influence in the nomogram for predicting non-interval cholecystectomy.

Conclusions: Having a TG18 grade III status, acalculous cholecystitis, severe hypoproteinemia, and a history of malignancy influence the failure to undergo cholecystectomy after PC in patients with acute cholecystitis.

Keywords: Acute cholecystitis, Percutaneous cholecystostomy, Cholecystectomy

\section{Background}

Acute cholecystitis (AC) is a common surgical emergency. Its pathophysiology is mainly derived from the obstruction of the cystic duct of the gallbladder or

*Correspondence: cmuwisdom@126.com

Department of Radiology, Shengjing Hospital of China Medical University,

No. 36, Sanhao Street, Heping District, Shenyang 110004, China dyskinesia of its wall, which can lead to increased intraluminal pressure, wall edema, wall ischemic necrosis, or perforation, thereby increasing the probability of bacterial reproduction in the cavity [1]. Although laparoscopic cholecystectomy (LC) is the gold standard for the treatment of AC, LC may be accompanied by high morbidity and mortality in cases of acute inflammation or in 
high-risk patients, such as the elderly, those with multiple comorbidities, or the critically ill [2-5].

Percutaneous cholecystostomy (PC) is an effective method for treating moderate or severe $\mathrm{AC}$ in high-risk patients. Its purpose is to adequately drain the gallbladder to resolve the acute course and prevent local and systemic complications. Related research indicates that PC followed by delayed cholecystectomy has better clinical outcomes than emergency LC [6-8]. Therefore, PC is being increasingly utilized as a bridging therapy before definitive therapy [9].

Some guidelines suggest that patients should undergo interval cholecystectomy to prevent the relapse of AC following the resolution of AC symptoms through PC [10]. However, some patients still fail to undergo interval cholecystectomy because of various reasons. To the best of our knowledge, there are few reports regarding the factors that prevent patients from undergoing interval cholecystectomy.

Therefore, in this study, we retrospectively analyzed the medical records of patients with cholecystitis who had undergone PC in our tertiary teaching hospital, followed up on the subsequent definitive management of the patients initially treated with PC, and explored the factors influencing their failure to undergo interval cholecystectomy.

\section{Methods}

\section{Study participants}

This study was a retrospective review of the data of all patients with AC treated via PC at the Shengjing Hospital of China Medical University, between January 1, 2017 and December 31, 2019. We obtained the demographic and clinical information of patients with cholecystitis from the hospital information system. Consecutive data were collected through a nonselective process.

Patients diagnosed with AC according to the Tokyo Guidelines 2018 (TG18) and who had undergone PC after multidisciplinary evaluation were included [11], and those who had concomitant acute pancreatitis or were lost to follow-up were excluded from the analysis. This study was approved by the ethics committee of our hospital (approval number: 2020PS704K). The requirement of obtaining informed consent from the patients was waived owing to the retrospective nature of the study.

All PC procedures were performed by interventional radiologists under the guidance of ultrasound combined with fluoroscopy, with 100\% technical success. A 5F puncture needle (Cook, USA) was introduced into the gallbladder using the Seldinger technique with real-time sonographic visualization (TERASON2000, Terason, USA). Thereafter, an $8 \mathrm{~F}$ pigtail multiuse drainage catheter (Bard, USA) was introduced into the cystic cavity under fluoroscopic guidance (Fig. 1).

\section{Variables and definitions}

Based on the literature and our clinical experience, variables were defined as follows. PC-related complications included clogged and dislodged tubes. All-cause death referred to the death of the patient during the follow-up period. History of malignancy referred to the diagnosis of various malignant tumors before performing PC,

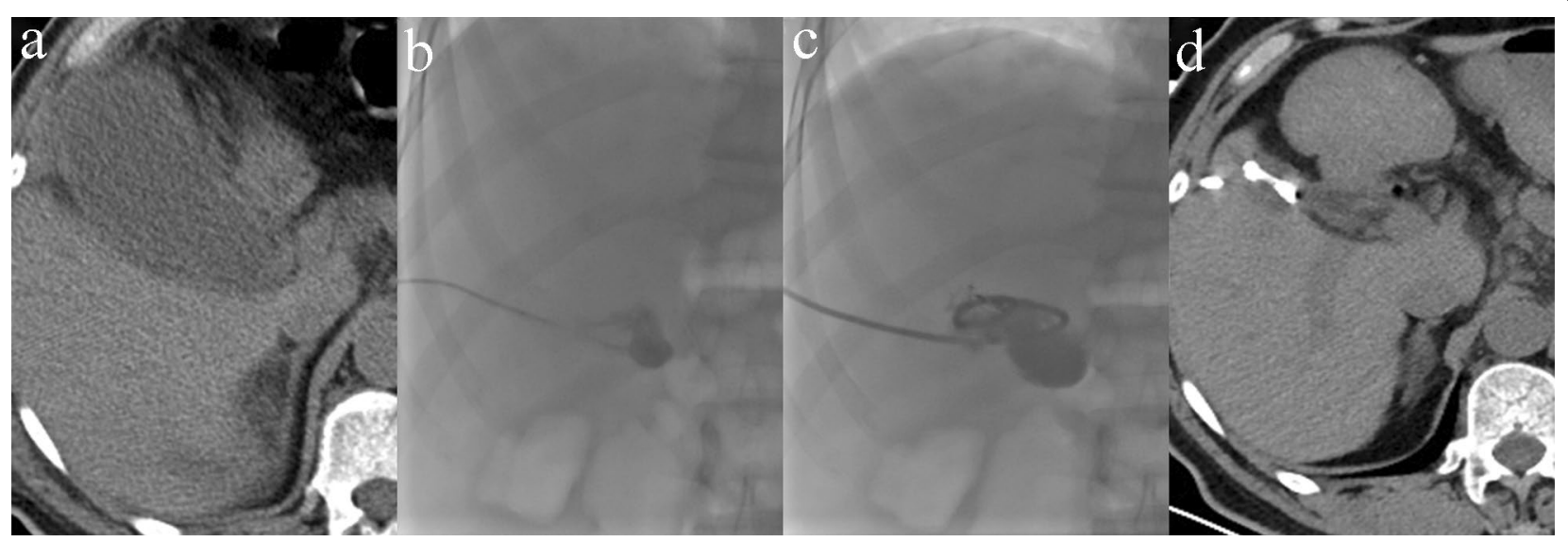

Fig. 1 The procedure of percutaneous cholecystostomy. a A 59-year-old man was diagnosed with acute acalculous cholecystitis on the 7th day after colon cancer surgery. Computed tomography (CT) showed gallbladder dilatation and gallbladder wall thickening with peripheral exudation. b The patient could not tolerate cholecystectomy; therefore, percutaneous cholecystostomy was performed to relieve the patient's symptoms. Ultrasound guided percutaneous puncture of the gallbladder was successfully confirmed by contrast injection. c An 8F pigtail drainage catheter was introduced into the gallbladder under fluoroscopic guidance. $\mathbf{d}$ Three months later, CT showed that the gallbladder had retracted, and the surrounding exudation was absorbed. However, the patient was still unable to tolerate cholecystectomy and had a long-term indwelling PC tube 
including previous history of malignancy and current malignancy. Kidney disease referred to all diseases that cause structural damage or dysfunction of the kidney, which mainly include glomerulonephritis, nephrotic syndrome, secondary nephropathy, chronic kidney disease, and chronic renal failure (CKD stage $\geq 3$ or glomerular filtration rate $\left.<60 \mathrm{ml} /\left(\min \cdot 1.73 \mathrm{~m}^{2}\right)\right)$. Patients with any of the following diseases were defined as having cardiovascular and cerebrovascular diseases (CCVD): heart failure, coronary atherosclerotic heart disease, myocardial infarction, arrhythmia, cerebral ischemia, cerebral hemorrhage, and stroke [12].

\section{Follow-up}

All patients who had undergone PC therapy were followed up. If the patient had undergone cholecystectomy, the follow-up was terminated. For patients who did not undergo cholecystectomy, we recommended follow-ups at our interventional radiology clinic every three months. If a patient was unable to visit the clinic, follow-up by phone was performed until the patient's death.

\section{Statistical analyses}

Continuous variables that satisfied the normal distribution were expressed as mean \pm standard deviation. Categorical variables were expressed as percentages and frequencies. Discrete variables were presented as medians and interquartile ranges (IQRs). Continuous or discrete variables were compared using the Mann-Whitney U test or the Kruskal-Wallis test. Categorical data were analyzed using the chi-square test or Fisher's exact test, as appropriate. Subjects were divided into two groups according to whether they had undergone interval cholecystectomy. To compare the differences between the two groups, we set non-interval cholecystectomy as a column stratification variable and the remaining variables as analysis variables to obtain a description of the study population between the two groups. Multivariate logistic regression models were used to identify independent risk factors associated with the patients' failure to undergo cholecystectomy during follow-up, and a nomogram was constructed on this basis. We adjusted for potential confounding factors such as age, sex, and candidate variables with $p<0.05$ in the univariate analysis. The results are presented as odds ratios (ORs) and $95 \%$ confidence intervals (CIs). A $p$-value $<0.05$ was considered statistically significant. All analyses were performed using Empower (R) (www.empowerstats.com, X\&Y solutions, Inc.) and R (http://www.R-project.org; version 3.4.3).

\section{Results \\ Baseline characteristics of the patients}

Overall, 205 patients were selected in this study. The patient selection flowchart is presented in Fig. 2. The average age of the patients was $67.3 \pm 14.7$ years, and $53.7 \%$ of them were male. The patients were followed up until February 7, 2021, and 138 of the 205 patients underwent interval cholecystectomy. The average time from PC to cholecystectomy was 3.3 months. Overall, 67 patients did not undergo interval cholecystectomy,

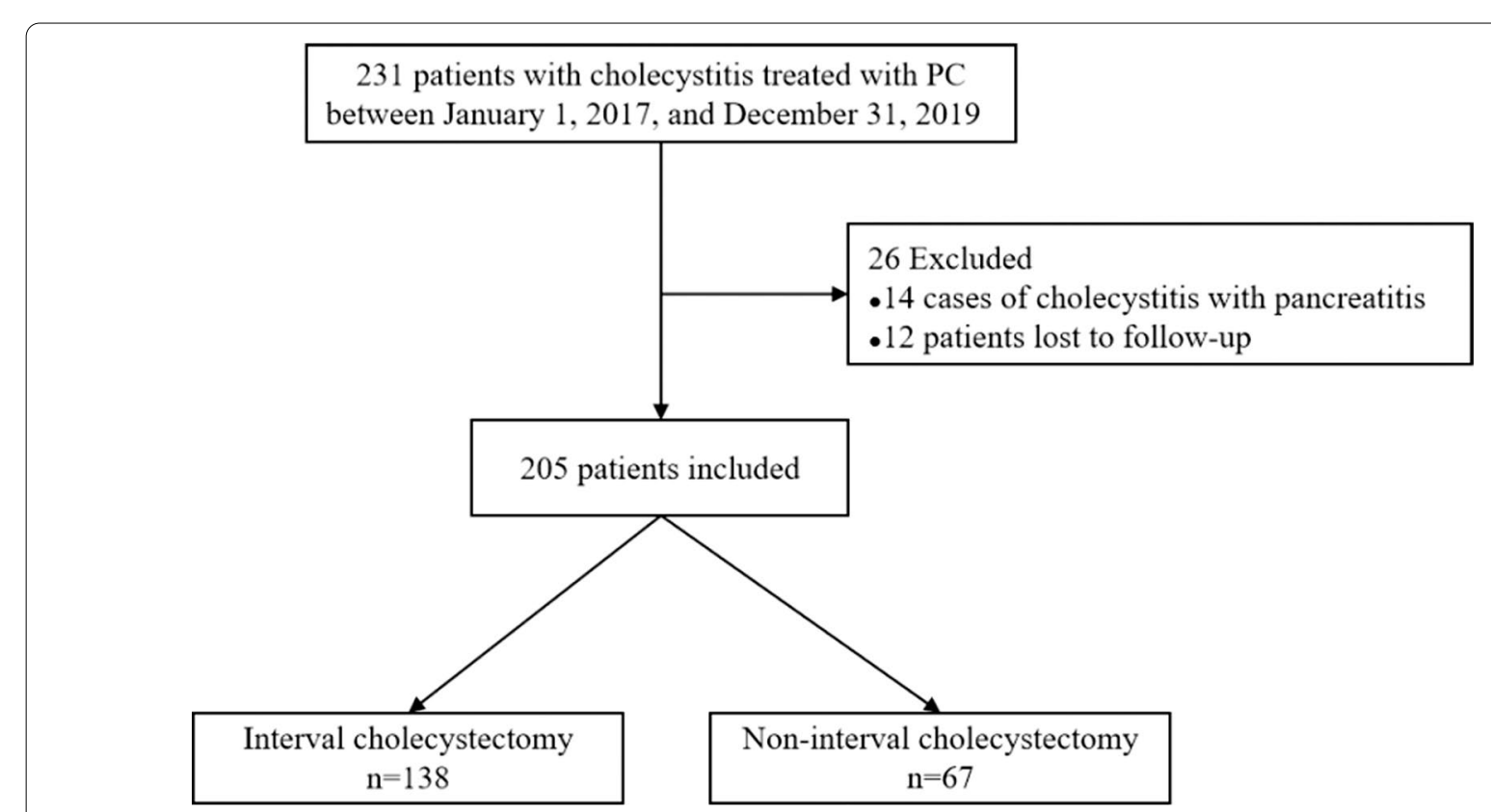

Fig. 2 Flowchart of the participant selection process 
including 21 who had long-term indwelling PC tubes and 46 who had their drainage tubes removed upon meeting the requirements in the clamping tests $[13,14]$. The participants' demographic and clinical characteristics with respect to whether they underwent interval cholecystectomy are shown in Table 1 . The average age of the

Table 1 Demographic and clinical characteristics of the patients included in the study

\begin{tabular}{|c|c|c|c|}
\hline & $\begin{array}{l}\text { Interval cholecystectomy } \\
(n=138)\end{array}$ & $\begin{array}{l}\text { Non-interval cholecystectomy } \\
(n=67)\end{array}$ & $P$-value \\
\hline Age (years) & $64.33 \pm 14.61$ & $73.40 \pm 12.97$ & $<0.001$ \\
\hline Sex & & & 0.754 \\
\hline Female & $65(47.10 \%)$ & $30(44.78 \%)$ & \\
\hline Male & $73(52.90 \%)$ & $37(55.22 \%)$ & \\
\hline TG18 grade & & & $<0.001$ \\
\hline Grade I & 95 (68.84\%) & $38(56.72 \%)$ & \\
\hline Grade II & $32(23.19 \%)$ & $10(14.93 \%)$ & \\
\hline Grade III & $11(7.97 \%)$ & $19(28.36 \%)$ & \\
\hline \multicolumn{4}{|l|}{ Laboratory test } \\
\hline White blood cell $\left(\times 10^{9} / \mathrm{L}\right)$ & $12.20(8.12-15.68)$ & $10.16(7.32-14.90)$ & 0.956 \\
\hline Direct bilirubin ( $\mu \mathrm{mol} / \mathrm{L})$ & $11.60(6.10-19.50)$ & $10.00(5.47-46.92)$ & 0.099 \\
\hline Total bilirubin ( $\mu \mathrm{mol} / \mathrm{L})$ & $22.40(13.60-37.90)$ & $21.80(11.50-61.70)$ & 0.238 \\
\hline Aspartate aminotransferase (U/L) & $26.00(18.00-53.00)$ & $25.00(17.00-53.00)$ & 0.566 \\
\hline Alanine aminotransferase (U/L) & $26.00(16.00-60.00)$ & $23.00(15.00-61.00)$ & 0.164 \\
\hline Serum creatinine $(\mu \mathrm{mol} / \mathrm{L})$ & $69.20(55.70-87.25)$ & $69.30(51.80-106.90)$ & 0.494 \\
\hline INR & $1.22 \pm 0.13$ & $1.35 \pm 0.80$ & 0.096 \\
\hline Platelet $\left(\times 10^{9} / \mathrm{L}\right)$ & $189.37 \pm 68.98$ & $183.49 \pm 76.10$ & 0.587 \\
\hline Albumin stratification (g/L) & & & 0.004 \\
\hline$>35$ & $42(41.58 \%)$ & $11(24.44 \%)$ & \\
\hline $28-35$ & $50(49.50 \%)$ & $21(46.67 \%)$ & \\
\hline$<28$ & $9(8.91 \%)$ & $13(28.89 \%)$ & \\
\hline \multicolumn{4}{|l|}{ Image performance } \\
\hline Gallbladder distention (>4 cm) & $129(93.48 \%)$ & $65(97.01 \%)$ & 0.292 \\
\hline Thickened gallbladder wall (>3 mm) & $135(97.83 \%)$ & $64(95.52 \%)$ & 0.359 \\
\hline Gallstones & $118(85.51 \%)$ & $41(63.08 \%)$ & $<0.001$ \\
\hline Common bile duct stones & $27(19.57 \%)$ & $14(21.54 \%)$ & 0.744 \\
\hline Common bile duct dilatation (> $6 \mathrm{~mm}$ ) & $34(24.64 \%)$ & $17(25.37 \%)$ & 0.909 \\
\hline Pericholecystic effusion & $70(50.72 \%)$ & $33(49.25 \%)$ & 0.843 \\
\hline \multicolumn{4}{|l|}{ Comorbidity } \\
\hline Hypertension & $48(34.78 \%)$ & $30(44.78 \%)$ & 0.167 \\
\hline Diabetes & $23(16.67 \%)$ & $14(20.90 \%)$ & 0.460 \\
\hline Cardiovascular and cerebrovascular diseases & $40(28.99 \%)$ & $34(50.75 \%)$ & 0.002 \\
\hline History of malignancy & $11(7.97 \%)$ & $18(26.87 \%)$ & $<0.001$ \\
\hline Liver cirrhosis & $2(1.45 \%)$ & $0(0.00 \%)$ & 0.322 \\
\hline Kidney disease & $4(2.90 \%)$ & $4(5.97 \%)$ & 0.287 \\
\hline \multicolumn{4}{|l|}{ Postoperative } \\
\hline Septic shock & $4(2.90 \%)$ & $4(5.97 \%)$ & 0.287 \\
\hline Transfer to ICU & $4(2.90 \%)$ & $2(2.99 \%)$ & 0.972 \\
\hline Hospitalization days & $7(5-11)$ & $6(4-10)$ & 0.713 \\
\hline PC-related complications & $4(2.90 \%)$ & $5(7.46 \%)$ & 0.353 \\
\hline Clogged tube & $2(1.45 \%)$ & $1(1.49 \%)$ & 0.981 \\
\hline Dislodged tube & $2(1.45 \%)$ & $4(5.97 \%)$ & 0.072 \\
\hline Recurrence after PC & $19(13.77 \%)$ & $15(22.39 \%)$ & 0.120 \\
\hline All-cause deaths during follow-up & $1(0.72 \%)$ & $19(28.36 \%)$ & $<0.001$ \\
\hline
\end{tabular}


patients who did not undergo interval cholecystectomy was higher than that of those who underwent cholecystectomy ( $73.40 \pm 12.97$ vs. $64.33 \pm 14.61$ years; $p<0.001)$. Significant differences in terms of the TG18 grade, albumin level, presence of gallstones, presence of CCVD, history of malignancy, and number of all-cause deaths were observed between the two groups.

\section{Analysis of factors influencing patients' failure to undergo interval cholecystectomy}

The univariate regression analysis showed that age and having a TG18 grade III status, acalculous cholecystitis, an albumin level $<28 \mathrm{~g} / \mathrm{L}, \mathrm{CCVD}$, and a history of malignancy were the factors influencing a patient's failure to undergo interval cholecystectomy. Of these factors, having a TG18 grade III status, acalculous cholecystitis, an albumin level $<28 \mathrm{~g} / \mathrm{L}$, and a history of malignancy were independent risk factors for failure to undergo interval cholecystectomy, as per the multiple regression analysis (further details are shown in Table 2). A regression coefficient-based nomogram was constructed from the significant variables (Fig. 3). The presence of a history of malignancy had the highest influence in the nomogram in terms of predicting non-interval cholecystectomy.

\section{Discussion}

$\mathrm{PC}$ as a bridge to cholecystectomy or as a definitive treatment has been increasingly used as an alternative initial treatment option for patients with AC. However, 60-70\% of patients with $\mathrm{AC}$ do not undergo interval cholecystectomy after PC [15-18]. In our study, 67 (32.7\%) patients did not undergo interval cholecystectomy after PC, which is considerably lower than that in previous studies [15-18].

Interestingly, our study found that in addition to age, a TG18 grade III status, hypoproteinemia, CCVD, and a history of malignancy contributed to the patients' failure to undergo subsequent cholecystectomy. Among these factors, a TG18 grade III status, hypoproteinemia, and a history of malignancy were independent risk factors that negatively influenced the decision to pursue cholecystectomy. In addition, univariate and multivariate analyses showed that patients with calculous cholecystitis were more likely to undergo cholecystectomy. Although age and the presence of CCVD were not independent risk factors in this study, advanced age and CCVD limit the patients' ability to undergo surgical procedures that require general anesthesia.

With a Grade III AC, the patient's overall status usually deteriorates significantly, with one or more organ dysfunctions. Such patients usually have numerous underlying diseases. Even if their cholecystitis is eventually controlled through PC, the patient's poor physical condition affects their decision to undergo interval cholecystectomy. For patients with a Charlson Comorbidity Index score $\geq 4$ or an American Society of Anesthesiologists physical status $\geq 3$, the TG18 recommends that conservative treatments should be considered as an alternative to definitive surgery [19].

Gallstones are extremely common [10], and approximately $78.6 \%$ of the patients in our study presented with acute calculous cholecystitis. PC can drain the infected bile or pus from the gallbladder and rapidly de-escalate the inflammation and infection status of a patient with cholecystitis. However, PC cannot resolve the high-risk factors for the recurrence of biliary events, such as the presence of gallstones [20, 21]. Although cholecystectomy is the gold standard for the treatment of gallstones and cholecystitis, patients who have undergone PC could still be poor candidates for cholecystectomy and may require permanent gallbladder drainage. $\mathrm{PC}$ tube removal after the resolution of $\mathrm{AC}$ is an option; however, cholecystitis recurrence rates range from 22 to $41 \%$, mainly due to gallstones [21-23]. Previous attempts to develop minimally invasive definitive treatment options for gallstones have focused on percutaneous gallstone removal, intraluminal sclerosis, and cryoablation [24-26]. These treatment modalities are promising future alternatives to cholecystectomy in patients with permanent indwelling PC tubes.

Table 2 Risk factor analysis for a patient's failure to undergo interval cholecystectomy

\begin{tabular}{|c|c|c|c|c|c|}
\hline \multirow[t]{2}{*}{ Variables } & \multirow[t]{2}{*}{ Statistics } & \multicolumn{2}{|c|}{ Univariate analysis } & \multicolumn{2}{|c|}{ Multivariate regression analysis } \\
\hline & & OR $(95 \% \mathrm{Cl})$ & $P$ value & OR $(95 \% \mathrm{Cl})$ & $P$ value \\
\hline Age (years) & $67.29 \pm 14.70$ & $1.05(1.03,1.08)$ & $<0.001$ & $1.02(0.99,1.06)$ & 0.202 \\
\hline TG18 grade III & $30(14.63 \%)$ & $4.57(2.03,10.31)$ & $<0.001$ & $3.83(1.27,11.49)$ & 0.017 \\
\hline Acalculous cholecystitis & $44(21.46 \%)$ & $3.33(1.67,6.67)$ & $<0.001$ & $4.55(1.59,12.50)$ & 0.005 \\
\hline Albumin $(\mathrm{g} / \mathrm{L})<28$ & $22(15.07 \%)$ & $4.15(1.62,10.63)$ & 0.003 & $4.15(1.09,15.81)$ & 0.037 \\
\hline $\begin{array}{l}\text { Cardiovascular and cerebrovascu- } \\
\text { lar diseases }\end{array}$ & $74(36.10 \%)$ & $2.52(1.38,4.62)$ & 0.003 & $2.12(0.87,5.17)$ & 0.099 \\
\hline History of malignancy & $29(14.15 \%)$ & $4.24(1.87,9.62)$ & $<0.001$ & $4.65(1.62,13.37)$ & 0.004 \\
\hline
\end{tabular}

Cl confidence interval, OR odds ratio, TG18 Tokyo Guidelines 2018 
Point 0 10 20 30 40 $50 \quad 60$ 70 80 $90 \quad 100$

TG18 grade III

Albumin $<28 \mathrm{~g} / \mathrm{L}$

Acalculous cholecystitis Acalculous cholcystitis

History of malignancy

Total points

Linear predictor

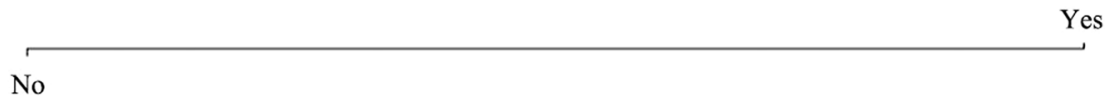

Yes

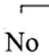

No

Yes

No

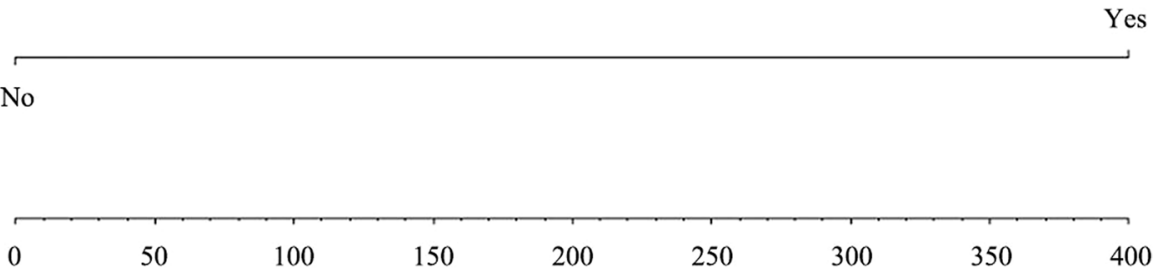

\begin{tabular}{rllllll}
\hline & -1 & 0 & 1 & 3 & 4
\end{tabular}

Probability of non-interval

cholecystectomy

0.2

0.6

0.9

Fig. 3 Nomogram for predicting the probability of non-interval cholecystectomy. Top: the predictor points are found on the uppermost point scale that corresponds to each variable. Bottom: the points for all variables are added and translated into the probability of non-interval cholecystectomy

Hypoproteinemia is an indicator of poor liver function, which is also a factor influencing the patient's inability to undergo cholecystectomy. This condition also means that the patients are malnourished, which poses a challenge during cholecystectomy performed under general anesthesia.

The expected survival time has a crucial impact on the decision to perform surgery. For patients with a history of malignancy, especially with advanced-stage tumors, a limited survival time and gradual deterioration of their physical condition contribute to their unsuitability to cholecystectomy. In our study, the mortality of the patients who did not undergo cholecystectomy during the follow-up period was as high as $28.36 \%$, which was significantly higher than the mortality in the cholecystectomy group. Malignant tumors were the main cause of death in these patients.

In our study, 21 patients had long-term indwelling PC tubes, whereas 46 patients had their drainage tubes removed. Instead of analyzing these two groups of patients separately, we combined them into the noninterval cholecystectomy group. Furthermore, because of the limitations of retrospective research, for some patients, we could not determine whether the patients had an objective inability to undergo cholecystectomy or whether they had a subjective unwillingness to undergo the procedure. These are the main deficiencies of our research and may have impacted our conclusions. Nevertheless, this is the first study based on a real-world analysis of the factors influencing patients' failure to undergo cholecystectomy. In addition, we presented a nomogram for individualized risk estimation that allows for the calculation of the numerical probability of undergoing cholecystectomy after PC among patients with AC. We also believe that it is important for clinicians to communicate with patients before $\mathrm{PC}$ regarding the possibility of undergoing subsequent cholecystectomy. 


\section{Conclusion}

In conclusion, a TG18 grade III status, acalculous cholecystitis, severe hypoproteinemia, and a history of malignancy influence the failure to undergo cholecystectomy after PC among patients with $\mathrm{AC}$.

\section{Abbreviations}

AC: Acute cholecystitis; CCVD: Cardiovascular and cerebrovascular diseases; Cl: Confidence interval; LC: Laparoscopic cholecystectomy; OR: Odds ratio; PC: Percutaneous cholecystostomy; TG18: Tokyo Guidelines 2018.

\section{Acknowledgements}

Not applicable.

\section{Authors' contributions}

YP analyzed the data, prepared figures and/or tables, and wrote the paper. ZC and ZL reviewed and edited the paper. All authors read and approved the final manuscript.

\section{Funding}

The study was supported by the National Natural Science Foundation of China (Grant No. 81901856) and the 345 Talent Project of the Shengjing Hospital of China Medical University.

\section{Availability of data and materials}

The datasets analyzed during the current study are available from the corresponding author on reasonable request.

\section{Declarations}

\section{Ethics approval and consent to participate}

This study was conducted in strict accordance with the Declaration of Helsinki and approved by the ethical committee of Shengjing Hospital of China Medical University (Approval Number: 2020PS704K). Informed consent was waived by the ethical committee of Shengjing Hospital of China Medical University due to the retrospective nature of this study.

\section{Consent for publication}

Not applicable.

\section{Competing interests}

The authors declare that they have no competing interests.

Received: 19 June 2021 Accepted: 20 October 2021

Published online: 29 October 2021

\section{References}

1. Aroori S, Mangan C, Reza L, Gafoor N. Percutaneous cholecystostomy for severe acute cholecystitis: a useful procedure in high-risk patients for surgery. Scand J Surg. 2019;108(2):124-9.

2. Huber DF, Martin EW, Cooperman M. Cholecystectomy in elderly patients. Am J Surg. 1983:146(6):719-22.

3. Houghton PW, Jenkinson LR, Donaldson LA. Cholecystectomy in the elderly: a prospective study. Br J Surg. 1985;72(3):220-2.

4. Loozen CS, van Ramshorst B, van Santvoort HC, Boerma D. Early cholecystectomy for acute cholecystitis in the elderly population: a systematic review and meta-analysis. Dig Surg. 2017:34(5):371-9.

5. Winbladh A, Gullstrand P, Svanvik J, Sandström P. Systematic review of cholecystostomy as a treatment option in acute cholecystitis. HPB. 2009;11(3):183-93.

6. Atar E, Bachar GN, Berlin S, Neiman C, Bleich-Belenky E, Litvin S, et al. Percutaneous cholecystostomy in critically ill patients with acute cholecystitis: complications and late outcome. Clin Radiol. 2014;69(6):e247-52.

7. Karakayali FY, Akdur A, Kirnap M, Harman A, Ekici Y, Moray G. Emergency cholecystectomy vs percutaneous cholecystostomy plus delayed cholecystectomy for patients with acute cholecystitis. Hepatobiliary Pancreat Dis Int. 2014;13(3):316-22.

8. Simorov A, Ranade A, Parcells J, Shaligram A, Shostrom V, Boilesen E, et al. Emergent cholecystostomy is superior to open cholecystectomy in extremely ill patients with acalculous cholecystitis: a large multicenter outcome study. Am J Surg. 2013;206(6).

9. Mukai S, Itoi T, Baron TH, Takada T, Strasberg SM, Pitt HA, et al. Indications and techniques of biliary drainage for acute cholangitis in updated Tokyo Guidelines 2018. J Hepatobiliary Pancreat Sci. 2017:24(10):537-49.

10. Ansaloni L, Pisano M, Coccolini F, Peitzmann AB, Fingerhut A, Catena F, et al. 2016 WSES guidelines on acute calculous cholecystitis. World J Emerg Surg: WJES. 2016;11:25

11. Yokoe M, Hata J, Takada T, Strasberg SM, Asbun HJ, Wakabayashi G, et al. Tokyo Guidelines 2018: diagnostic criteria and severity grading of acute cholecystitis (with videos). J Hepatobiliary Pancreat Sci. 2018;25(1):41-54.

12. Li N, Zhou H, Tang Q. Red blood cell distribution width: a novel predictive indicator for cardiovascular and cerebrovascular diseases. Dis Markers. 2017:2017:7089493.

13. Cha BH, Song HH, Kim YN, Jeon WJ, Lee SJ, Kim JD, et al. Percutaneous cholecystostomy is appropriate as definitive treatment for acute cholecystitis in critically ill patients: a single center, cross-sectional study. Korean J Gastroenterol. 2014;63(1):32-8.

14. Park JK, Yang J-I, Wi JW, Park JK, Lee KH, Lee KT, et al. Long-term outcome and recurrence factors after percutaneous cholecystostomy as a definitive treatment for acute cholecystitis. J Gastroenterol Hepatol. 2019;34(4):784-90.

15. Hung Y-L, Sung C-M, Fu C-Y, Liao C-H, Wang S-Y, Hsu J-T, et al. Management of patients with acute cholecystitis after percutaneous cholecystostomy: from the acute stage to definitive surgical treatment. Front Surg. 2021;8:616320.

16. Loftus TJ, Collins EM, Dessaigne CG, Himmler AN, Mohr AM, Thomas RM et al. Percutaneous cholecystostomy: prognostic factors and comparison to cholecystectomy. Surg Endosc. 2017;31(11):4568-75.

17. Viste A, Jensen $D$, Angelsen $J H$, Hoem D. Percutaneous cholecystostomy in acute cholecystitis; a retrospective analysis of a large series of 104 patients. BMC Surg. 2015;15:17.

18. Ha JPY, Tsui KK, Tang CN, Siu WT, Fung KH, Li MKW. Cholecystectomy or not after percutaneous cholecystostomy for acute calculous cholecystitis in high-risk patients. Hepatogastroenterology. 2008;55(86-87):1497-502.

19. Okamoto K, Suzuki K, Takada T, Strasberg SM, Asbun HJ, Endo I, et al. Tokyo Guidelines 2018: flowchart for the management of acute cholecystitis. J Hepatobiliary Pancreat Sci. 2018;25(1):55-72.

20. Turiño SY, Shabanzadeh DM, Eichen NM, Jørgensen SL, Sørensen LT, Jørgensen LN. Percutaneous cholecystostomy versus conservative treatment for acute cholecystitis: a cohort study. J Gastrointest Surg. 2019;23(2):297-303.

21. Hung Y-L, Chong S-W, Cheng C-T, Liao C-H, Fu C-Y, Hsieh C-H, et al. Natural course of acute cholecystitis in patients treated with percutaneous transhepatic gallbladder drainage without elective cholecystectomy. J Gastrointest Surg. 2020;24(4):772-9.

22. Horn T, Christensen SD, Kirkegård J, Larsen LP, Knudsen AR, Mortensen FV. Percutaneous cholecystostomy is an effective treatment option for acute calculous cholecystitis: a 10-year experience. HPB. 2015;17(4):326-31.

23. Sanjay P, Mittapalli D, Marioud A, White RD, Ram R, Alijani A. Clinical outcomes of a percutaneous cholecystostomy for acute cholecystitis: a multicentre analysis. HPB. 2013;15(7):511-6.

24. Kim YH, Kim YJ, Shin TB. Fluoroscopy-guided percutaneous gallstone removal using a 12-Fr sheath in high-risk surgical patients with acute cholecystitis. Korean J Radiol. 2011;12(2):210-5.

25. Xu Z, Wang L, Zhang N, Ling X, Hou C, Zhou X. Chemical ablation of the gallbladder: clinical application and long-term observations. Surg Endosc. 2005;19(5):693-6.

26. McGregor H, Woodhead G, Patel M, Khan A, Hannallah J, Ruiz D, et al. Gallbladder cryoablation for chronic cholecystitis in high-risk surgical patients: 1-year clinical experience with imaging follow-up. J Vasc Intervent Radiol: JVIR. 2020;31(5):801-7.

\section{Publisher's Note}

Springer Nature remains neutral with regard to jurisdictional claims in published maps and institutional affiliations. 